in the volume of the endolymph with distension of the membranous labyrinth. ${ }^{3}$ Reisner's membrane may rupture leading to mixing of perilymph and endolymph. ${ }^{34}$ Healing then occurs, but succeeding acute episodes are associated with further ruptures. The sensory elements of the ear atrophy. ${ }^{3}$ These changes may be secondary to syphilis, Paget's disease of bone, or otosclerosis. ${ }^{12}$ Delayed endolymphatic hydrops may follow a variety of insults to the inner ear. ${ }^{5}$ The term Menière's disease should be reserved for idiopathic cases.

The hydrops results from disturbed endolymphatic homoeostasis, but how this happens is not clear. Some believe that abnormalities of the stria vascularis lead to overproduction of endolymph, while others blame blockage of the endolymphatic duct or disordered absorption in the endolymphatic sac. Alternatively, metabolites may accumulate in the endolymph causing an increase in its volume by osmosis. Blocking the endolymphatic duct or disrupting the sac in animals produces hydrops after a variable interval. ${ }^{6-8}$ Some surgeons have reported during operations on the endolymphatic sac that its wall appears ischaemic in Menière's disease but not in other conditions. ${ }^{9}$ Histological studies show perisacular fibrosis, reduced vascularity, and abnormalities of the epithelial elements of the sac. ${ }^{3910}$ Blockage of the endolymphatic duct has also been reported. ${ }^{911}$

About $5 \%$ of patients have a family history of the disease. ${ }^{12}$ Vasomotor disturbances may be an underlying cause, a theory supported by the finding that a third of these patients also suffering from migraine. ${ }^{12}$ Allergic problems have also been implicated, but, though food allergies are found in some patients, there is no overall increase in the prevalence of allergy in patients with Menière's disease compared with controls. ${ }^{13}$ Viral infections and endocrine disturbances have also been suggested as causes. ${ }^{1}$ Psychological factors may also be important: patients with the disease score highly for anxiety, obsessionality, and depression.

All treatments for Menière's disease are hard to assess because some patients experience long remissions whatever is done. Many patients may be managed medically. Surgery is usually reserved for those in whom medical treatment fails, but some surgeons advocate early conservative surgery to preserve hearing. ${ }^{2}$ Vasodilators such as betahistine, ${ }^{14}$ vestibular sedatives such as cinnarizine or prochlorperazine, ${ }^{15}$ and diuretics such as hydrochlorothiazide ${ }^{16}$ are all used, and medical "decompression" of the labyrinth may be attempted with a low salt diet. Vestibular function may be destroyed with streptomycin sulphate, ${ }^{17}$ which may be particularly useful in bilateral Menière's disease as hearing may be preserved. ${ }^{18}$

The simplest surgical treatment practised is insertion of a ventilation tube into the tympanic membrane, but it is difficult to see why stabilisation of middle ear pressure should influence pathology in the inner ear. ${ }^{1}$ Some surgical treatments that were once widely used-such as cervical sympathectomy ${ }^{19}$ and destroying vestibular function with ultrasound ${ }^{20}$ - have become less popular. Decompression of the endolymphatic sac is now one of the commonest surgical treatments. $^{2122}$ It is an easy, safe operation that appears logical, but a trial against cortical mastoidectomy showed no difference in the results. ${ }^{23}$

Vertigo may be eliminated but hearing preserved by section of the vestibular nerve via either middle or posterior cranial fossa approaches. ${ }^{24} 25$ These operations are effective, but risks and morbidity are greater than for other operations. Labyrinthectomy produces consistent improvement in vertigo but also complete deafness in the operated ear. ${ }^{26} \mathrm{~A}$ translabyrinthine vestibular nerve section may also be performed.

Senior Registrar,

Ear, Nose, and Throat Department, ROBERT Mills $\stackrel{\frac{c}{c}}{\stackrel{\partial}{c}}$

King's College Hospital,

London SE5 9RS

1 Ludman H. Cochleovestibular diseases. In: Mawson SR, Ludman H. Diseases of the ear. London: Edward Arnold, 1979:490-8.

Morrison AW. Endolymphatic hydrops. In: Management of sensorineural deafness. London: Butterworths, 1975:145-74.

Hallpike CS, Cairns H. Observation of the pathology of Menière's syndrome. Proceedings of the Royal Society of Medicine 1938;31:1317-36

4 Schuknecht HF. Pathophysiology of Menière's disease. Am 7 Otol 1984;5:526-7

4 Schuknecht HF. Pathophysiology of Meniere's disease. Am fot Otol 1984;5:526-7.

6 Naito T. Experimental studies on Menière's disease. Otorhinological Society of Japan (Tokyo) 1970;79:754-6.

Kimura RS. Experimental blockage of the endolymphatic duct and sac and its effect on the inner ear of the Guinea pig. Ann Otol Rhinol Laryngol 1967;76:664-87.

8 Schuknecht HF, Norhtrop C, Igarashi M. Cochlear pathology after destruction of the endolymphatic sac in the cat. Acta Otolaryngol (Stockh) 1968;65:479-87.

9 Shambaugh GE, Clemis JP, Arenberg IK. Endolymphatic duct and sac in Menière's disease. Arch Otolaryngol 1969;89:816-25.

10 Arenberg IK, Marowitz WF, Shambaugh GE Jr. The role of the endolymphatic sac in the pathogenesis of endolymphatic hydrops in man. Acta Otolaryngol (Stockh) (Suppl) 1970;275: pathog.

11 Schuknecht HF. Pathology of Menière's disease as it relates to sac and tac procedures. Ann Otol Rhinol Laryngol 1977;86:677-82.

2 Morrison AW. Menière's disease. Journal of the Royal Society of Medicine 1981;74:183-9. 12 Morrison AW. Menière's disease. Fournal of the Royal Society of Medicine 1981;74:183-9.
13 Moffatt DA, Booth JB, Morrison AW. Metabolic investigations in Menière's disease. F Lanyngol of
Otol 1979:93:545-56.

Otol 1979;93:545-56.
Wilmot TJ. The effect of betahistine hydrochloride in Menière's disease. Acta Otolanyngol (Stockh) (Suppl) 1970;305:18-21. 5 Hinchcliffe R. Review of treatment of Menière's disease. Acta Otolaryngol (Stockh) (Suppl)
(1970;305:10-7.

16 Klockhoff I, Lindbaum U. Menière's disease and hydrochlorthiazide: a critical analysis of symptoms and therapeutic effects. Acta Otolaryngol (Stockh) 1967;63:347-65.

7 Schuknecht HF. Ablation therapy for Menière's disease. Acta Otolaryngol (Stockh) (Suppl) 1957;32:14-32.

18 Graham MD, Kemink JL. Titration streptomycin therapy for bilateral Menière's disease: a progress report. Am $\mathcal{F}$ Otol 1984;5:534-5.

19 Passe ERG, Seymour JS. Menière's syndrome: successful treatment by surgery on the sympathetic. Br Med f 1948;ii:812-6.

Angell-James J. Menière's disease: The present status of ultrasonic therapy. Arch Otolanyngol 1969;89:95-7.

21 Portmann G. Vertigo: Surgical treatment by opening the saccus endolymphaticus. Arch Otolaryngol 1927;6:309-19.

22 House WF. Subarachnoid shunt for drainage of hydrops: a preliminary report. Laryngoscope 1962;72:713-29.

23 Thomsen J, Bretlau P, Tos M, Johnsen NJ. Placebo effect of surgery in Menière's disease. Arch Otolaryngol 1981;107:271-81.

24 Fisch U. Vestibular and cochlear neurectomy. Transactions of the American Academy of Ophthalmology and Otolaryngology 1974;78:1450-501.

25 Silverstein $\mathrm{H}$, Norell $\mathrm{H}$. Retrolabyrinthine total vestibular neurectomy. Otolanyngol Head Neck Surg 1982;90:778-82.

26 Cawthorne $T$. Some recent work on the investigation and treatment of Menière's disease. Proceedings of the Royal Sociery of Medicine 1943;36:541-6.

\section{Immunity and depression}

There are good reasons for studying immunity in depression. Stress, which is closely associated with depression, affects immune responses, and its physiological consequences are now being defined more precisely. ${ }^{1}$ Corticosteroids mediate $N$ some of the effects of stress on immune function, but other hormones and peptides synthesised by the central nervous system, such as $\beta$ endorphin, are also important. In addition, lymphocyte responses to mitogen stimulation in vitro are $\stackrel{\mathscr{?}}{+}$ depressed after bereavement, and similarly impaired re- 0 sponses and lymphopenia have been recorded in medical students during their examinations at Ohio State University, an institute not especially noted for academic harshness. ${ }^{2} 3$

More directly, physiological changes that might affect immune responses have been noted in depressed patients. The noradrenergic system seems to be abnormally activated, and this seems to induce excessive cortisol secretion. Rubin et al have shown that plasma concentrations of 3-methoxy-4hydroxyphenylglycol are raised in depressed patients, sug- 
gesting that there is increased noradrenergic turnover; and cortisol secretion in many depressed patients is not suppressible by dexamethasone, reflecting abnormal activation of the hypothalamic pituitary adrenal axis. ${ }^{4}$ Excessive cortisol production might itself affect immune function, since lymphocytes carry adrenergic and cholinergic receptors, making them directly susceptible to altered neuroendocrine function. ${ }^{5}$ Plasma concentrations of prostaglandins $E_{1}$ and $E_{2}$ are also increased in depressed patients, and these substances affect immune reactions indirectly by their effects on the hypothalamic control of adrenal function and more directly by their actions on antigen presenting cells. ${ }^{6}$ Those who attribute depressive illnesses and schizophrenia to autoimmune mechanisms might also expect abnormalities in conventional immune functions. ${ }^{78}$

Most studies of the immune responses of depressed patients have analysed the relative and absolute numbers of blood lymphocyte populations. Lymphocyte function has also been tested by measuring the in vitro proliferative responses of $T$ cells to concanavalin $\mathrm{A}$ and phytohaemagglutinin and of $\mathrm{B}$ cells to pokeweed mitogen. Assays of humoral immunity have been based almost exclusively on determining serum immunoglobulin concentrations. The initial reports claimed that in vitro responsiveness to mitogens was reduced in depressed patients. ${ }^{9}$ But the same group subsequently found normal in vitro responses to mitogens but a mild $T$ lymphopenia in depressed patients not needing admission to hospital. ${ }^{10}$ They inferred that impaired immunity was confined to patients with severe illness, but the differences between patients and controls were not compelling, particularly given the wide variation in $\mathrm{T}$ cell counts even among controls.

More tellingly, others found that the lymphocyte responses of 27 patients with different depressive illnesses were the same before treatment as those in 13 normal controls." After treatment with tricyclic antidepressants, lithium, or electroconvulsive therapy in vitro responses to phytohaemagglutinin and concanavalin A were reduced, emphasising the need to take treatment into account. These results suggest that altered lymphocyte function is not related to the pathogenesis of depression. A more detailed analysis of lymphocyte populations using monoclonal antibodies showed no differences between a few depressed patients and controls. ${ }^{6}$ These workers found impaired in vitro responses to mitogen stimulation, which they attributed to raised plasma prostaglandin concentrations, but their studies were limited and need further analysis.

The evidence for defective humoral immunity in depressed patients is also fragmentary. Reduced plasma IgM concentrations were found in few of the 85 patients admitted to a psychiatric unit; the reduction was also noted in six patients with depressive illnesses. ${ }^{12}$ In contrast, the pattern of serum and cerebrospinal fluid immunoglobulins was essentially normal in a group of patients with psychiatric diseases which included seven patients with depression. ${ }^{13}$ There is a dearth of information about specific antibody responses in depressed patients.

Hence little suggests that immune reactions are appreciably altered in depressive illnesses. Moreover, few studies have taken into account the many factors such as treatment, diet, and lifestyle that influence immune response. Even if one were to accept that depressive illnesses are associated with perturbed lymphocyte responses, there is sparse evidence that the changes matter. For example, there is little indication that specific antimicrobial immunity is depressed by depressive illnesses. Some data, however, suggest that an inextricable mixture of stress and depression predisposes to disorders with an immunological basis - for example, emotional stress may precede the onset of rheumatoid arthritis. ${ }^{14}$ Nevertheless, it would be wrong to assume that impaired immunity secondary to depressive illness must initiate such diseases, even if the epidemiological evidence for such associations is strong.

Those who believe that altered immune reactions predispose to depressive illnesses or are an important consequence of such disorders must analyse the responses more closely linked to relevant host defences. Furthermore, they must take concomitant treatment into account. ${ }^{6}{ }^{11}$ The anti-inflammatory effects of antidepressants might be related to their therapeutic efficacy, but it has still to be shown that these effects are more than a pharmacological irrelevance. ${ }^{15}$

A M DENMAN

Consultant Physician,

Connective Tissue Disease Research Group,

Clinical Research Centre,

Harrow HA1 3UJ

1 Stein M, Keller SE, Schieifer SJ. Stress and immunomodulation: the role of depression and neuroendocrine function. I Immunol 1985;135:827-33.

2 Schieifer SJ, Keller SE, Camerino M, Thornton JC, Stein M. Suppression of lymphocyte stimulation following bereavement. JAMA 1983;250:374-7.

3 Glaser R, Kiecolt-Glaser JK, Stout JC, Tarr KL, Speicher CE, Holliday JE. Stress-related impairments in cellular immunity. Psychiatry Res 1985;16:233-9.

Rubin AL, Price LH, Charney DS, Heninger GR. Noradrenergic function and the cortisol response to dexamethasone in depression. Psychiatry Res 1984;15:5-15.

5 Pochet R, Delespesse G, Gauseet PW, Collet H. Distribution of beta-adrenergic receptors on human lymphocyte sub-populations. Clin Exp Immunol 1979;38:578-84.

6 Calabrese JR, Skwerer RG, Barna B, et al. Depression, immunocompetence, and prostaglandins of the E series. Psychiatry Res 1985;27:41-7.

the E series. Psychiatry Res 1985;27:41-7.
7 Pandey RS, Gupta AK, Chaturvedi UC. Autoimmune model of schizophrenia with special Pandey RS, Gupta AK, Chaturvedi UC. Autoimmune model of
reference to antibrain antibodies. Biol Psychiatry 1981;16:1123-36.

reference to antibrain antibodies. Biol Psychiatry 1981;16:1123-36.
8 Knight JG. Dopamine-receptor-stimulating autoantibodies: A possible cause of schizophrenia. Lancet 1982;ii: 1073-5.

Schieifer SJ, Keller SE, Meyerson AT, Raskin MJ, Davis KL, Stein M. Lymphocyte function in major depressive disorder. Arch Gen Psychiatry 1984;41:484-6.

10 Schliefer SJ, Keller SE, Siris SG, Davis KL, Stein M. Depression and immunity: lymphocyte function in ambulatory depressed patients, hospitalized schizophrenic patients, and patients hospitalized for herniorrhaphy. Arch Gen Psychiatry 1985;42:129-33.

11 Albrecht J, Helderman JH, Schlesser MA, Rush AJ. A controlled study of cellular immune function in affective disorders before and during somatic therapy. Psychiaty Res 1985;15:185-93.

12 DeLisi LE, King AC, Targum S. Serum immunoglobulin concentrations in patients admitted to an acute psychiatric in-patient service. Br $\mathcal{F}$ Psychiatry 1984;145:661-6.

13 Roos RP, David K, Meltzer HY. Immunoglobulin studies in patients with psychiatric diseases. Arch Gen Psychiatry 1985;42:124-8.

14 Baker GHB, Brewerton DA. Rheumatoid arthritis: a psychiatric assessment. Br Med $\mathcal{J}$ 1981;282:20.

15 Hong SL, Carty T, Deykin D. Tranylcypromine and 15-hydroperoxyarachidonate affect arachidonic acid release in addition to inhibition of prostacyclin synthesis in calf aortic endothelial cells. I Biol Chem 1980;255:9538-40.

\section{Dietary supplementation in pregnancy}

Give me neither poverty nor riches, feed me with food convenient for me.

PROVERBS XXX, 8

The quality of diet has long been known to affect the fetal condition, a better maternal diet being associated with better condition of the offspring. ${ }^{\prime}$ Extremes of diet, such as those in the Dutch famine in the second world war or associated with obesity, ${ }^{2}$ are well recognised as adversely affecting the outcome of pregnancy, but marginal imbalances are less well understood. In underdeveloped nations with their immense problems of malnutrition the benefits of supplementation may be dramatic, ${ }^{3}$ but in affluent Western society its value is less certain.

Investigations of the effects of additional calories or a high protein diet during pregnancy have given conflicting results. A New York study of a poor black urban population suggested marginal benefits from balanced supplementation, 